\title{
Materialização da reforma contábil no setor público: análise de municípios de pequeno e médio porte da Zona da Mata Mineira
}

\author{
Gabriela Brandão Lopes \\ Universidade Federal de Viçosa (UFV) \\ Gislaine Aparecida Santana Sediyama \\ Universidade Federal de Viçosa (UFV) \\ Rodrigo Silva Diniz Leroy \\ Universidade Federal de Viçosa (UFV) \\ Joyce Santana Bernardo \\ Universidade Federal de Viçosa (UFV)
}

Este estudo busca compreender o grau de atenção que os municípios de pequeno e médio porte estão atribuindo à adoção das novas normas de contabilidade pública e quais os mecanismos utilizados no processo de materialização dessa reforma, a fim de revelar o isomorfismo das ações implementadas pelos gestores. Por meio de entrevistas com contadores e secretários de finanças de oito municípios da Zona da Mata Mineira, foi possível constatar comportamento isomórfico mimético e normativo entre os municípios ao se apoiarem em associações de municípios e empresas de software para acessar o conteúdo da reforma. Constatou-se que a profissionalização dos gestores se mostrou relevante e as empresas de software assumem papel de difusoras da reforma, responsáveis por implementar as normas, oferecer suporte e treinar a equipe. Conclui-se que as inovações propostas pela reforma têm sido implementadas e estão aderentes às demandas institucionais, mas que as restrições financeiras e estruturais têm limitado esse processo.

Palavras-chave: contabilidade pública - reforma, inovação, implementação, administração municipal

[Artigo recebido em 12 de janeiro de 2017. Aprovado em 31 de julho de 2018.] 
Materialización de la reforma contable en el sector público: análisis de municipios de pequeño y medio porte de la Zona de la Mata Minera

Este estudio busca comprender el grado de atención que los municipios de pequeño y mediano tamaño están atribuyendo a la adopción de las nuevas normas de contabilidad pública y cuáles los mecanismos utilizados en el proceso de materialización de esa reforma, a fin de revelar isomorfismo de las acciones implementadas por los gestores. Por medio de entrevistas con contadores y secretarios de finanzas de ocho municipios de la Zona de la Mata Minera, fue posible constatar comportamiento isomórfico mimético y normativo entre los municipios al apoyarse en asociaciones de municipios y empresas de software para acceder al contenido de la reforma. Se constató que la profesionalización de los gestores se mostró relevante y las empresas de software asumen papel de difusoras de la reforma, responsables de implementar las normas, brindar soporte y entrenar al equipo. Se concluye que las innovaciones propuestas por la reforma han sido implementadas y están adheridas a las demandas institucionales, pero que las restricciones financieras y estructurales han limitado ese proceso.

Palabras clave: contabilidad pública - reforma, innovación, implementación, administración municipal

Materialization of accounting reform in the public sector: analysis of small and medium municipalities of the Zona da Mata Mineira

This study seeks to understand the degree of attention from small and medium size cities in the new public accounting standards and what are the mechanisms used in the materialization of this reform in order to reveal isomorphism of the actions implemented by the managers. Through interviews with accountants and finance secretaries of eight cities in the Mata de Minas Gerais area, we have verified mimetic and normative isomorphic behavior, that support itself in associations of municipalities and software companies to access the content of the reform. We verified that the professionalization of the managers proved to be relevant and the software companies assumed the role of diffusers of the reform, responsible to implement the norms, to offer support and to train the team. We concluded that the innovations proposed by the reform have been implemented and are confluent to institutional demands, but that financial and structural constraints have limited this process.

Keywords: public accounting - reform, innovation, implementation, municipal administration 


\section{Introdução}

A institucionalização das normas internacionais de contabilidade pública no Brasil traz em seu escopo não só o anseio de modernizá-la, mas estabelecer um conjunto de normas que permitam uniformização consensual dos princípios contábeis e das boas práticas governamentais pelos entes federados.

Regulamentada até 2008 pelos dispositivos da Lei no 4.320/64, da Constituição Federal de 1988, da Lei Complementar no 101/2000 (Lei de Responsabilidade Fiscal) e da Lei no 10.028 , de 2000, a contabilidade pública brasileira centrava-se na elaboração e controle dos balanços, dos orçamentos, e na gestão fiscal dos entes federados.

Em 2008, o Ministério da Fazenda publicou a Portaria no 184, dispondo diretrizes quanto aos procedimentos, práticas, elaboração e divulgação das demonstrações contábeis, de forma a torná-las convergentes com as Normas Internacionais de Contabilidade Aplicadas ao Setor Público (IPSAS). Com isso, foi estabelecida a mudança do enfoque contábil, eminentemente centrado no controle orçamentário, para um enfoque pautado no patrimônio do ente público.

Nesse processo, a contabilidade pública brasileira passou a ter como objeto principal o patrimônio do ente, além de adotar o regime de competência para receitas e despesas, que obriga o reconhecimento na ocorrência do fato gerador, em detrimento do registro a partir da movimentação dos recursos em caixa (DARós; Pereira, 2009; Cruvinel; LIMA, 2011).

A Secretaria do Tesouro Nacional (STN), responsável pelo estabelecimento de diretrizes, normas e procedimentos contábeis aos entes da Federação, estabeleceu cronograma com prazos para implantação das mudanças a partir da Portaria STN no 634/2013. Definiu que o Plano de Contas Aplicado ao Setor Público (PCASP) e as Demonstrações Contábeis Aplicadas ao Setor Público (DCASP) deveriam ser adotados por todos os entes da Federação até o término do exercício de 2014. Além disso, determinou que os Procedimentos Contábeis Patrimoniais (PCP), definidos no Manual de Contabilidade Aplicada ao Setor Público (MCASP) e de observância obrigatória pelos entes da Federação, teriam prazos finais de implantação estabelecidos de forma gradual por meio de ato normativo da STN.

A ideia subjacente a essa implementação gradual remete ao fato das IPSAS estarem sendo implementadas a todos os entes da Federação (União, estados e municípios) simultaneamente, e ao fato de que esses entes possuem particularidades e realidades diferentes. Nesse sentido, deve se chamar a atenção para os municípios, uma vez que esses possuem características heterogêneas em termos de acesso a recursos financeiros, tecnológicos e de pessoal que podem 
restringir e dificultar o processo de implementação das novas práticas contábeis, principalmente em unidades de pequeno e médio porte. Gerick, Clemente e Taffarel (2010) apontam que essas características são fatores preocupantes, pois os municípios são fundamentais no atendimento às demandas da população pelo fato de o gestor público viver mais próximo da realidade local e, por consequência, poder intervir nessa realidade de modo mais efetivo.

Estratégias de cooperação intermunicipais e entre entidades de apoio local tendem a ser frequentes nesse processo e podem conduzir à adoção de comportamento isomórfico pelos municípios, ao adotarem práticas semelhantes que os auxiliem na adaptação à reforma e na obtenção de legitimidade. Principalmente quando se trata de municípios de pequeno e médio porte que estão distantes física e tecnologicamente dos órgãos emissores da reforma (situados em Brasília, Distrito Federal). Assim, emerge o seguinte questionamento: qual o nível de aderência das práticas implementadas pelos municípios de pequeno e médio porte às Normas Internacionais de Contabilidade Pública (IPSAS) implementadas no Brasil?

Dessa forma, o presente estudo tem por objetivo compreender o grau de atenção que esses municípios estão atribuindo às normas de contabilidade pública e quais mecanismos têm sido utilizados no processo de materialização dessa reforma. Como unidade de pesquisa, delimitaram-se os municípios de Viçosa (médio porte) e seus limítrofes (de pequeno porte), situados na Zona da Mata de Minas Gerais, devido às dificuldades geográficas e financeiras de municípios interioranos de pequeno e médio porte na realização de capacitações.

Estudos correlatos recentes têm analisado as implicações das novas normas da contabilidade pública no Brasil, seja sob uma perspectiva geral das normas em si (Vicente; Morais; Platt Neto, 2012), da forma como o Governo Federal abordou sua implementação (GAMA; DUQUE; ALMEIDA, 2013), ou analisando as adequações em localidades específicas (Bertulino et. al., 2012; Melo; Prieto; ANdRAde, 2014; Ravanello; Mercuzzo; Frey, 2015).

Este estudo inova e traz contribuição à literatura, visto que se utilizou da Teoria Institucional em seu pilar sociológico para investigar a implementação das novas normas de contabilidade pública em municípios específicos, pela percepção dos atores locais. Ademais, embora a institucionalização das IPSAS seja um fenômeno recente e em andamento no Brasil, este estudo permite compreender o quanto já se avançou com essa reforma em termos de adequação, formas de acesso do conteúdo da reforma e a efetiva participação dos órgãos responsáveis pela emissão da reforma (STN e Tribunal de Contas) em municípios de pequeno e médio porte, distantes física e tecnologicamente do centro emissor da reforma. 
Além dessa introdução, o estudo aborda no próximo tópico a institucionalização e o isomorfismo, além de aspectos teóricos centrais que fundamentam as análises dos casos. Em seguida, apresentam-se os procedimentos metodológicos, as análises das evidências e as considerações finais.

\section{Referencial teórico}

A abordagem da Teoria Institucional, fundamentada em conceitos como institucionalização, normas, mitos e legitimidade, pode ser sustentada pelas orientações econômica, política ou sociológica (CARVALHO; VIEIRA; LOPES, 1999). Neste trabalho, optou-se pelo pilar sociológico da teoria, baseado em, dentre outros, autores dos trabalhos seminais dessa orientação, como Meyer e Rowan (1977), Berger e Luckmanm (2004) e DiMaggio e Powell (1991, 2005).

\section{Isomorfismo como mecanismo institucionalizador}

As instituições são sistemas de regras estabelecidas e incorporadas por um grupo de indivíduos que, através dessas, estruturam suas interações sociais (HodGson, 2006). Emergem e se estruturam como resultado de interações e atividades, segundo um conjunto de regras, expectativas, crenças e símbolos compartilhados, chamados de "instituições" (ScOTT, 2007). Compreendem as premissas tomadas como certas, que corroboram e delineiam as ações dos atores individuais (BURNS; SCAPENS, 2000).

As ações tornadas habituais conservam seu caráter significativo para o indivíduo e conduzem o estabelecimento de rotinas (BERGER; LUCKMANM, 2004), que dependem de hábitos (Guerreiro; FrezATTI; CASADO, 2006). Esses hábitos são caracterizados como tendência para se engajar em formas de ação anteriormente adotadas e influenciarão o seguimento de regras. Nesse sentido, as rotinas moldam as instituições e desempenham papel importante na relação entre ações e instituições (BURNS; SCAPENS, 2000).

Cada organização possui seus mecanismos internos para suas ações (suas instituições) que, quando integrados em um sistema social em que um conjunto de organizações compartilham sistemas de significados comuns e interagem entre si, constituem uma área reconhecida da vida institucional denominada de campo organizacional (DIMAgGIO; POWELL, 2005).

Os campos organizacionais não são homogêneos, mas, quando o campo é altamente estruturado, as organizações são pressionadas a se assemelharem umas às outras para aumentar sua legitimidade, sem necessariamente tornaremse mais eficientes (DIMAgGIO; PoWELL, 1991, p. 65). Campos organizacionais 
mais estruturados proporcionam um contexto em que os esforços individuais de seus integrantes levam em conjunto à homogeneidade em estrutura, cultura e resultados, de forma racional com incerteza e restrição (DIMAGGIO; POWELL, 2005).

Meyer e Rowan (1977) afirmam que as organizações são levadas a incorporar práticas e procedimentos aceitos e institucionalizados, a fim de aumentar sua legitimidade perante a sociedade, independente da eficácia imediata dessas práticas e procedimentos. A incorporação das práticas e procedimentos se dá ao permitir que as organizações cumpram suas atividades e estabeleçam práticas e estruturas que as aproximem dos padrões considerados corretos perante a sociedade, auferindo recursos necessários à sua sobrevivência se conseguirem se tornar isomórficas no ambiente (MEYER; ROWAN, 1977; CHAVLEISHVILI, 2011).

Assim, quanto ao isomorfismo, DiMaggio e Powell (2005) estabelecem três mecanismos: coercitivo, mimético e normativo. Primeiramente, o isomorfismo coercitivo provém da influência política e do problema da legitimidade. Advém das pressões externas, como força da lei ou determinações governamentais, exercidas sobre as organizações para que adotem procedimentos ou técnicas semelhantes a outras organizações mais fortes (PACHECO, 2002).

O isomorfismo mimético, por sua vez, resulta de respostas a padrões de incerteza (DIMAGGIO; PoWELL, 2005). É produzido quando a organização passa por um momento de alta dúvida quanto a seus produtos ou serviços, ou também por conflitos quanto aos seus objetivos. Esse mecanismo faz com que a organização adote procedimentos e práticas já desenvolvidos por uma organização que atue em seu ambiente específico.

O isomorfismo normativo é associado à profissionalização das organizações, ao compartilhamento e à especialização de um conjunto de rotinas e normas de trabalho de determinada profissão ou ocupação (KELM et al., 2014). Surge a partir de mudanças que visam atender a determinados padrões e técnicas considerados pela comunidade dos profissionais como os mais atualizados e eficazes, sendo transmitidos por meio de treinamentos e legitimação entre os próprios profissionais (PACHECO, 2002).

DiMaggio e Powell (2005) identificam dois aspectos da profissionalização como fontes importantes de isomorfismo. O primeiro é o fato da educação formal e a sua legitimação, uma vez que as universidades e as organizações são importantes centros de desenvolvimento de normas organizacionais. O segundo aspecto é o crescimento e a elaboração de redes profissionais que perpassam as organizações por meio das quais novos modelos se difundem rapidamente; as associações profissionais e de investigação constituem outro veículo propício à formulação de normas profissionais. 
Para DiMaggio e Powell (2005), a institucionalização decorre de processos isomórficos, resultantes da assimilação de soluções utilizadas por outras instituições. Representa um processo compulsório que força as unidades de uma população a assemelharem-se a outras unidades que enfrentam os mesmos desafios. Assim, as estruturas formais das organizações surgem como reflexos de valores e normas institucionais, em um processo no qual a pressão do ambiente institucional posiciona-se numa atitude isomórfica em relação às instituições sociais.

Tolbert e Zucker (1999) apontam ser mais fácil disseminar novas estruturas entre as organizações do que criar estruturas semelhantes dentro de uma mesma organização, porque a percepção dos decisores sobre os custos e benefícios da adoção de determinadas práticas é influenciada pela observação do comportamento das outras organizações que funcionam como ambiente de "pré-teste".

\section{Procedimentos metodológicos}

Trata-se de estudo descritivo, de natureza qualitativa, em que se buscou compreender o grau de atenção que os municípios estão atribuindo às reformas contábeis e quais mecanismos têm sido utilizados na materialização dessa reforma. Assim, a pesquisa pode ser entendida como analítica ou explanatória, segundo a classificação de Collis e Hussey (2005).

Como unidade de investigação, foram delimitados oito municípios mineiros que fazem parte da microrregião de Viçosa, localizada na Zona da Mata de Minas Gerais. O município de Viçosa possui sete municípios limítrofes que, somados a ele, têm população de aproximadamente 138 mil habitantes, com um Produto Interno Bruto (PIB) de aproximadamente $\mathrm{R} \$ 1,857$ bilhões, conforme Tabela 1.

Tabela 1 - População estimada em 2015 e o PIB per capta dos municípios

\begin{tabular}{ccccccccc}
\hline $\begin{array}{c}\text { Dados dos } \\
\text { municípios }\end{array}$ & Viçosa & Teixeiras & $\begin{array}{c}\text { Porto } \\
\text { Firme }\end{array}$ & $\begin{array}{c}\text { Guara- } \\
\text { ciaba }\end{array}$ & $\begin{array}{c}\text { Paula } \\
\text { Cândido }\end{array}$ & Coimbra & $\begin{array}{c}\text { Mão } \\
\text { do } \\
\text { Anta }\end{array}$ & Cajuri \\
\hline $\begin{array}{c}\text { População } \\
\text { estimada* }\end{array}$ & 77,3 & 11,8 & 11,1 & 10,5 & 9,6 & 7,5 & 7,0 & 4,1 \\
\hline PIB (R\$)** & 1188,2 & 95,3 & 73,9 & 255,1 & 75,0 & 68,5 & 53,8 & 47,8 \\
\hline $\begin{array}{c}\text { PIB per cap- } \\
\text { ta (R\$)* }\end{array}$ & 15,6 & 8,1 & 6,7 & 24,3 & 7,8 & 9,2 & 7,7 & 11,6 \\
\hline
\end{tabular}

Fonte: IBGE $(2013,2016)$.

Nota: *em mil ** em milhões

Esse recorte foi feito devido à acessibilidade, disponibilidade e pela dificuldade de acesso dos gestores a treinamentos presenciais nos grandes centros, visto 
que a conexão entre os municípios interioranos e as capitais brasileiras é feita predominantemente por via terrestre, o que dificulta o acesso. Esse fator, conjugado às restrições financeiras de municípios de pequeno porte, limita a participação dos gestores municipais em atividades realizadas nos grandes centros urbanos, principalmente naqueles responsáveis pelo estabelecimento das reformas contábeis, como é o caso de Brasília/DF. Do mesmo modo, a frequência de participação de representantes desses órgãos nos municípios também é negativamente influenciada. Assim, as dificuldades financeiras e de acesso às atividades de treinamento motiva o uso de mecanismos alternativos para acessar as informações, como internet, consultorias e participação em associações de municípios.

As evidências foram coletadas por meio de entrevista semiestruturada (MARTINS; THEÓPHILO, 2007), in loco, entre os meses de outubro de 2015 a janeiro de 2016, com os responsáveis pelo setor contábil dos municípios estudados, que não serão identificados nominalmente. Como em um dos municípios o contador foi exonerado do cargo, o secretário de finanças respondeu aos questionamentos. Assim, contribuíram com o estudo sete contadores e um secretário de finanças, que serão identificados ao longo do estudo como Entrevistado 1 (E1) a Entrevistado 8 (E8).

Por fim, conforme orientações de Bardin (2011), para a análise de conteúdo, as evidências foram codificadas e agrupadas em duas categorias: 1) aderência às exigências legais, que revela o grau de adequação ou não do município às normas e aos prazos estabelecidos pela STN; e 2) mecanismos utilizados no processo de adoção, que permite compreender quais os mecanismos adotados na institucionalização da reforma e verificar se há ou não homogeneidade no comportamento adotado pelos municípios.

\section{Resultados}

Neste tópico serão apresentados, analisados e discutidos os resultados do trabalho, embasados nas legislações, nas respostas dos gestores e na literatura, sendo subdividido em dois sub-tópicos, conforme as categorias estabelecidas.

\section{Materialização da reforma contábil}

A Portaria STN no 634/13 estabeleceu como prazo para adoção do Plano de Contas Aplicado ao Setor Público (PCASP) e das Demonstrações Contábeis Aplicadas ao Setor Público (DCASP) o término do exercício de 2014, e destacou que a consolidação nacional e por esfera de governo das contas de 2014 deveria ser realizada no ano de 2015. 
Era necessário que os entes observassem as regras referentes à elaboração do PCASP e das DCASP, estabelecidas pelo Manual de Contabilidade Aplicado ao Setor Público (MCASP) divulgado pela STN. Caso não encaminhassem suas contas de acordo com o novo padrão de plano de contas, poderiam ficar impedidos de receber transferências voluntárias e de contratar operações de crédito, além de estarem sujeitos a outras restrições por parte do seu respectivo tribunal de contas. O Quadro 1 evidencia o estágio de aderência pelos municípios, além dessa exigência, aos demais procedimentos relacionados à reforma contábil.

Quadro 1 - Implementação dos procedimentos contábeis pelos municípios.

\begin{tabular}{|c|c|c|c|c|c|c|c|c|c|}
\hline \multirow{2}{*}{ Exigências Legais } & \multirow{2}{*}{$\begin{array}{l}\text { Prazo de } \\
\text { adoção }\end{array}$} & \multicolumn{8}{|c|}{ Nível de aderência por município* } \\
\hline & & E1 & E2 & E3 & E4 & E5 & E6 & E7 & E8 \\
\hline $\begin{array}{l}\text { Plano de Contas Aplicado ao Setor } \\
\text { Público }\end{array}$ & Até 2014 & $\mathrm{~T}$ & $\mathrm{~T}$ & $\mathrm{~N}$ & $\mathrm{~T}$ & $\mathrm{~T}$ & $\mathrm{~T}$ & $\mathrm{~T}$ & $\mathrm{~T}$ \\
\hline Demonstrações contábeis & Até 2014 & $\mathrm{~T}$ & $\mathrm{~T}$ & $\underline{P}$ & $\mathrm{~N}$ & $\mathrm{~N}$ & $\underline{P}$ & $\mathrm{~T}$ & $\mathrm{~T}$ \\
\hline Regime de competência & $\begin{array}{c}2017 \text { a } \\
2021\end{array}$ & $\mathrm{~N}$ & $\mathrm{~N}$ & $\mathrm{~T}$ & $\mathrm{~T}$ & $\mathrm{~N}$ & $\mathrm{~N}$ & $\mathrm{~T}$ & $\mathrm{~N}$ \\
\hline $\begin{array}{l}\text { Levantamento e registro dos bens } \\
\text { patrimoniais }\end{array}$ & 2010 & $\mathrm{~N}$ & $\mathrm{~T}$ & $\mathrm{~N}$ & $\mathrm{~N}$ & $\mathrm{~T}$ & $\mathrm{~T}$ & $\mathrm{~T}$ & $\mathrm{~T}$ \\
\hline $\begin{array}{l}\text { Depreciação, amortização e ex- } \\
\text { austão }\end{array}$ & $\begin{array}{c}2020 \text { e } \\
2021\end{array}$ & $\mathrm{~N}$ & $\mathrm{~N}$ & $\mathrm{~T}$ & $\mathrm{~N}$ & $\mathrm{~N}$ & $\mathrm{~N}$ & $\mathrm{~T}$ & $\mathrm{~T}$ \\
\hline Sistema de informação de custos & $N E^{*}$ & $\mathrm{~N}$ & $\mathrm{~N}$ & $\mathrm{~N}$ & $\mathrm{~N}$ & $\mathrm{~N}$ & $\mathrm{~N}$ & $\mathrm{~N}$ & $\mathrm{~N}$ \\
\hline
\end{tabular}

Fonte: Elaboração própria (2016).

*Legenda: E: entrevistado; T: aderiu totalmente às normas; P: aderiu parcialmente às normas; N: não aderiu às normas; NE: Não estipulado (a STN ainda não estipulou prazo para implementação dessa exigência).

Nota 1: Nem todos os procedimentos do MCASP estão contemplados no quadro, pois se referem a adequações terminológicas. Focando-se, portanto, aspectos práticos que influenciam a dinâmica do processo de adaptação.

Constatou-se que, dos municípios pesquisados, sete cumpriram o prazo de adoção do PCASP e um não. O entrevistado E3, único que não cumpriu a exigência no prazo estipulado, informou que o plano foi implementado em 2015 e que isso não ocorreu antes porque "não conseguimos adequar o software contábil a tempo suficiente para utilizar o novo modelo".

Como a consolidação das contas de 2014 era para o ano de 2015, o município não sofreu punição. Tal informação dá indícios de que a percepção sobre possíveis sanções pode ter sido o fator catalizador para o atendimento do prazo de adequação à mudança pela maioria dos municípios pesquisados. Esse aspecto reforça a tese de DiMaggio e Powell (1991), quando destacam que, quando as organizações de um campo efetuam transações com órgãos do Estado, maior é o grau de isomorfismo 
no campo como um todo, já que esse sofrerá uma pressão coercitiva para adoção de comportamento homogêneo.

Além das demonstrações contábeis exigidas pela Lei no 4.320/64, atualizadas pela Portaria STN no 438/2012, o MCASP destacou a obrigatoriedade de publicação da Demonstração dos Fluxos de Caixa (DFC) e da Demonstração das Mutações do Patrimônio Líquido (DMPL) e de Notas Explicativas (NE) junto ao Balanço Orçamentário, sendo facultada publicação da Demonstração do Resultado Econômico (DRE). Constatou-se que dois municípios ainda não implementaram essas demonstrações e outros dois o fizeram de maneira parcial.

A justificativa para a não implementação foi a falta de organização e planejamento interno, além de estarem desnorteados em relação ao que fazer primeiro. Para o entrevistado E4, "a quantidade de atividades no setor público já é imensa e é muita responsabilidade e peso em cima do contador". Ele afirma que ainda não adotou as DCASP, pois o prazo final de implementação iria até 2016 , o que não coincide com o que estabelece a Portaria STN no 634/13, ressaltando ainda que "tem coisas que para o município pequeno é a partir de 2022 (Subsistema de Custos)”.

Nos dois municípios em que a norma foi implementada parcialmente, os entrevistados afirmaram já terem implementado a DFC e a DRE, porém ainda não adotaram as NE. De acordo com E5, "as notas explicativas serão difíceis para fazer, pois nem tudo tem como ser explicado, até mesmo porque a contabilidade se baseia em atos e fatos". Para E6, "elaborar a NE vai ser uma coisa boa e importante, mas os cidadãos não enxergam desse jeito, porque não entendem essas informações. Por isso, não vemos necessidade de sua elaboração".

Em relação às outras exigências legais evidenciadas no Quadro 1, e diante das dificuldades encontradas pelos entes da Federação durante o processo de materialização da reforma, a STN elaborou um plano de implantação dos procedimentos patrimoniais no setor público e estipulou prazos limites de adequação, considerando as especificidades de procedimentos. No caso da adoção do regime de competência, foi estipulado como prazo 01/01/2021 para os municípios de até 50 mil habitantes e 01/01/2020 para os municípios acima de 50 mil habitantes, o que justifica o fato de cinco municípios ainda não terem adotado essa norma.

Para os entrevistados E1 e E2, essa mudança será "de grande impacto nas ações dos funcionários" e "muito complicada". Para E3, "pelo fato do município ainda não possuir uma contabilidade patrimonial estruturada, o impacto dessa mudança é muito grande". "São inúmeras mudanças e se não nos esforçarmos, não iremos conseguir adequar a tantos procedimentos", destacam os entrevistados. 
No intuito de se obter o correto registro de todos os bens do ente público, a Norma Brasileira de Contabilidade Técnica 16.5 (NBCT 16.5) estabelece alguns critérios de registro contábil dos atos e dos fatos que afetam ou possam vir a afetar o patrimônio das entidades do setor público. O prazo de adoção dessa exigência tornou-se obrigatório para todos os fatos ocorridos a partir de 01/01/2010, conforme evidenciado pelo Quadro 1. No entanto, constatou-se que três municípios ainda não implementaram tais exigências:

E1: "[SIC] ainda não estão todos os bens registrados, pois estão em fase de levantamento dos bens, e isso ainda não foi concluído, após a conclusão irá se efetuar o registro".

E3: “o município ainda não está adequado porque o controle interno ainda não terminou de fazer o levantamento, pois estão dando treinamentos e palestras com cada secretaria da cidade, a fim de ensinar a todos como devem ser efetuadas as compras e baixas dos objetos, seja porque estragou ou porque não é mais necessário".

E4: "ainda não foi realizado o levantamento dos bens de uso comum e bens intangíveis o município não possui".

Quando elementos do ativo imobilizado possuírem vida útil econômica limitada, esses ficam sujeitos ao processo de contabilização da depreciação, amortização ou exaustão durante esse período (BRASIL, 2016a). A NBC T 16.9 trouxe como exigência a obrigatoriedade de reconhecimento da depreciação, amortização ou exaustão, as circunstâncias que podem influenciar seu registro, além de reforçar que tais valores devem ser reconhecidos até que o valor líquido contábil do ativo seja igual ao seu valor residual. Desse modo, faz-se necessário o levantamento dos bens públicos, a mensuração de sua vida útil econômica e o reconhecimento da parcela a ser depreciada, amortizada ou exaurida mensalmente.

Em cinco municípios ainda não houve a implementação desses procedimentos. A principal justificativa é o fato de estarem na fase de levantamento dos bens, conforme pôde ser constatado com as seguintes afirmações.

E6: “[SIC] a depreciação não está sendo feita ainda, estão em processo de implantação ainda, estão fazendo meio que no chute de porcentagens".

E4: “[SIC] ainda não adotamos os procedimentos e a partir de 2016 vai complicar, porque terão muitas dificuldades em fazer depreciação e amortização. Quando os gestores se preocupam apenas com aspectos políticos, atrapalha as atividades do município, pois, se não existisse essa vontade política, iria se constituir uma equipe no município que ficaria responsável a executar essas atividades, estabelecendo prazos e metas. 
Quando se existe essa vontade política, as preocupações são outras. Aqui no município faltou vontade de trabalhar nessas atividades, justamente por esse aspecto político, em outro município de mesmo porte que eu trabalho aqui nessa mesma região, está tudo pronto, todo o levantamento dos bens públicos, a depreciação e amortização".

O Plano de Implantação dos Procedimentos Patrimoniais, elaborado pela STN (BRASIL, 2015), aponta que a depreciação dos bens móveis e imóveis para os municípios de até 50 mil habitantes deve ser realizada até 01/01/2021 e, para os que têm acima de 50 mil habitantes, esse prazo é até 01/01/2020. Tal resolução justifica o fato de cinco municípios em estudo ainda não terem institucionalizado plenamente tal exigência.

Cabe considerar que $\mathrm{E} 4$ salientou trabalhar em outro município próximo à região em estudo, que já institucionalizou quase 100\% das NBCASP "faltando apenas completar o processo de adoção do Sistema de Informação de Custos que está sendo implementado de forma gradual". De acordo com E4, no outro município em que atua:

[SIC] o gestor se preocupa com a administração municipal e não com aspectos políticos, o que facilitou muito a aceitação dos funcionários em relação às NBCASP e levou à implementação de todos os procedimentos exigidos. [...] a vontade política atrapalha as atitudes de todos os funcionários do município, pois a sua equipe começa a postergar atividades.

Além disso, E4 destaca que "se os indivíduos não entendem a importância de uma mudança, isso dificulta o processo". Tal afirmação reforça o pensamento de Guerreiro, Pereira e Rezende (2008), quando afirmam que na formação inicial e no desenvolvimento das instituições, os comportamentos e ações se tornam habituais na medida em que são evocados com um mínimo esforço de tomada de decisão pelos atores sociais, a fim de obterem respostas a estímulos particulares.

À medida que esses hábitos se tornam formalizados e institucionalizados, são reconhecidos como rotinas, as quais incorporam comportamentos e procedimentos orientados por regras, sendo fortalecidas pelo processo de repetição de ações para atender a essas regras (Meyer; Rowan, 1977; Guerreiro; PereirA; Rezende, 2008). Na visão de Quinello (2007), o aumento do grau de objetivação e exterioridade de uma ação também aumenta o grau de institucionalização, indicado pela conformidade dos indivíduos ao comportamento de outros.

Num contexto geral, dentre os municípios investigados, no município onde E7 trabal ha houve maior nível de aderência às novas normas, já que não se adequaram apenas ao sistema de informação de custos, que não tem prazo estipulado para 
implementação. Por outro lado, os municípios em que E1, E4 e E5 atuam são os menos adequados, posto que aderiram apenas a duas das seis exigências da reforma contábil. No próximo tópico serão abordados os mecanismos de adoção de que se utilizam os municípios na adequação à exigência do Subsistema de Informação de Custos.

\section{Mecanismos de adoção}

Uma das principais inovações no processo de harmonização aos padrões internacionais é a implementação de subsistemas de informação de custos no setor público. Sua finalidade é proporcionar instrumentos de análise para a eficácia, eficiência, economicidade e avaliação dos resultados do uso do recurso público (BRASIL, 2016b). Como a STN ainda não estipulou prazos para a adoção de tal procedimento, nenhum dos oito municípios em análise o adotaram, conforme o Quadro 1. Foi questionado aos entrevistados se e como a adoção desse sistema tem sido trabalhada na prefeitura, quais os procedimentos e estudos foram ou estão sendo realizados.

Os entrevistados destacaram que a implementação desse subsistema será feita de forma gradual e sistemática, considerando o longo prazo dado pela STN, ressaltando que se apoiam em softwares contábeis comercializados por empresas de informática para auxílio nesse processo.

Segundo os entrevistados, essas empresas estão estudando as exigências do STN e o modo como elas deverão ser implementadas nos municípios. "A ideia é que eles desenvolvam o sistema dentro dos moldes exigidos e, em seguida, ofereçam cursos de treinamento e consultorias aos gestores e servidores municipais". A afirmativa dos entrevistados deixa claro que as empresas de software são canais de difusão da informação da reforma contábil no setor público local e os municípios buscam se apoiar nas diretrizes passadas por elas, como forma de auferir legitimidade e convergência progressiva aos termos normativos. Nesse sentido, as empresas de software podem ser consideradas fonte de isomorfismo mimético, já que partilham as mesmas soluções a todos os municípios para os quais prestam os mesmos serviços.

Os gestores esperam que empresas prestadoras desses serviços, externas à prefeitura, compreendam as normas relativas ao sistema de informações de custos, elaborem um software para que as prefeituras possam utilizare prestem treinamentos a respeito, o que revela uma relação de dependência prefeitura-empresa. 
A afirmação feita por E4 reforça esse aspecto ao destacar que:

[SIC] O software AGP dá suporte e oferece treinamentos. [...] Em se falando de capacidade e o nível dos treinamentos é muito baixo, o nível dos municípios é muito baixo, não existe investimento em contabilidade por parte do gestor, pois a contabilidade não dá voto. Tem alguns treinamentos oferecidos pelo TCE-MG e também alguns oferecidos pela STN. Os cursos oferecidos pela STN são online e são mais restritos, pois o custo é muito alto, acaba não sendo vantajoso. Tem alguns treinamentos regionalizados, mas não apresentam novidades, logo, acabamos não indo.

As organizações são influenciadas por pressões normativas do Estado e de outros organismos reguladores, fazendo com que busquem se adaptar aos procedimentos e estruturas para se tornarem isomórficas, atendendo, assim, às expectativas do contexto (CARVALHo; VIEIRA, 2012). Isso é comprovado com as imposições legais sobre a contabilidade diariamente, um processo de constantes mudanças e imposições, o que leva as prefeituras a buscar mecanismos e outras organizações pertencentes ao mesmo campo organizacional, para conseguir institucionalizar algumas práticas em seu cotidiano.

Assim, outro importante ator envolvido nesse processo são as associações dos municípios, entidades que auxiliam e dão apoio aos municípios de uma mesma região, influenciam a estruturação do campo organizacional e contribuem para adoção de comportamentos isomórficos. Na região estudada, três associações apoiam e participam efetivamente junto às prefeituras: a Associação de Municípios da Zona da Mata Norte (AMMAN), localizada em Viçosa-MG; a Associação de Municípios do Vale do Piranga (Amapi), localizada em Ponte Nova-MG; e a Associação dos Municípios Mineiros (AMM), localizada em Belo Horizonte-MG.

Dos entrevistados, E3 e E5 afirmaram participar dos encontros promovidos pela AMMAN, por considerá-los uma oportunidade de troca de informações e por oferecerem cursos e treinamentos. Por outro lado, os que não participam dos encontros têm posicionamentos distintos. Na percepção de E2, a "[SIC] AMMAN não é mais o que era antes, não realiza mais encontros, quase fechou as portas". Para E4, "a AMMAN quis nascer muito grande e isso não funcionou"; o entrevistado acredita que "a Amapi está mais bem vista pela sociedade no momento", embora não tenha destacado sua contribuição em termos de treinamentos relativos à reforma contábil.

De acordo com E2, "a AMAPI está mais bem estruturada atualmente que a AMMAN, por isso participamos dos encontros em Ponte Nova-MG". Já E1 diz participar dos encontros da AMAPI e afirmou que "a associação oferece cursos e 
treinamentos nesses encontros. É ótima oportunidade para trocarmos informações e ideias com outros profissionais de outras prefeituras".

Por fim, os entrevistados E4, E6, E7 e E8 disseram participar dos encontros em Belo Horizonte-MG oferecidos pela AMM. Nesses encontros participam os secretários e funcionários municipais que, após as reuniões da associação, repassam as informações e ideias debatidas para os demais funcionários do município.

Em seus discursos, os entrevistados procuraram deixar claro que nesses eventos os profissionais dos municípios se encontram e debatem temas variados, inclusive as mudanças contábeis no setor público. Há troca de experiências, aprofundamento de conhecimento e dicas entre os profissionais. Esses aspectos reforçam as hipóteses de DiMaggio e Powell (2005) de que, quanto mais incerta for a relação entre meios e fins, tanto maior será a chance da organização moldar-se às outras cujas técnicas considera bem-sucedidas.

Questionados sobre o relacionamento do município com os órgãos reguladores envolvidos no processo de implementação das NBCASP, como a STN, o Conselho Federal de Contabilidade (CFC) ou os Tribunais de Contas dos Estados (TCE), os respondentes afirmaram manter relacionamento meramente técnico, como prestação de contas e publicações, atendendo apenas às disposições mínimas legais. E8 relata possuir "relacionamento mediano, pois os órgãos reguladores buscam o desenvolvimento, mas não dão suporte para isso, o que torna o relacionamento puramente técnico com a prestação de contas".

Assim, em termos de configuração, percebeu-se que o campo organizacional no qual as prefeituras estão inseridas se estrutura mais nas relações com as empresas de prestação de serviços contábeis, do que com as associações de municípios e órgãos reguladores.

A fim de identificar a ocorrência ou não de comportamentos isomórficos miméticos e normativos, foi questionado aos entrevistados se os gestores municipais se espelham em outros municípios ou se contratam profissionais que já têm conhecimento no tema para auxiliar no processo de adoção da reforma. Em três municípios os gestores se espelharam no trabalho desenvolvido por profissionais da área contábil que prestam consultorias às prefeituras da região.

E2 afirmou se espelhar em um município da região que, para ele, é muito organizado. O gestor se utiliza dos eventos organizados pela Amapi para trocar informações com os funcionários desse município, buscando se adequar às novas exigências, através de mecanismos já utilizados, para tentar se legitimar perante a sociedade. Essa atitude é aderente à percepção de DiMaggio e Powell (2005), quando afirmam que a utilização de mecanismos isomórficos miméticos é 
característica de organizações que buscam sair do momento de incerteza e visam à legitimidade perante seu ambiente.

E1 e E8 disseram não se espelhar em nenhum município ou profissional nesse processo de implementação, enquanto E4 afirma que "não nos motivamos nem nos espelhamos em nenhuma organização. Nos motivamos e espelhamos em profissionais contábeis do setor público". E6 foi enfático ao afirmar que "[SIC] nos espelhamos no prefeito do município de Divinésia-MG, por ser um profissional correto, sábio, ouvindo opiniões e buscando correções em conjunto, e considerado por muitos como ótimo administrador".

Carvalho e Vieira (2012) afirmam que a ação de indivíduos compreende artifício capaz de legitimar as organizações. Assim, para alcançar a legitimidade, as organizações tendem a reproduzir determinadas normas e procedimentos seguidos e validados por outras organizações, o que cria a uniformidade das regras, normas, mitos e crenças institucionalizadas, denominada de isomorfismo.

Em relação à terceira fonte de mudanças organizacionais, o isomorfismo normativo, DiMaggio e Powell (2005, p. 79) destacam que ele "deriva principalmente da profissionalização", uma vez que possibilita a disseminação de normas e padrões aceitos como corretos para as mais variadas ações organizacionais, o estabelecimento de base cognitiva e a concessão de legitimidade.

Nesse aspecto, constatou-se neste trabalho que em apenas um município o gestor do executivo municipal possui a característica da profissionalização, sendo contador e pós-graduado em perícia contábil. De acordo com E7, ter uma pessoa formada atuando na gestão municipal "facilita muito o trabalho do município, pois o gestor percebe muito a importância de uma legislação baseada na legislação internacional, e oferece todo suporte para a implementação ocorrer da melhor forma possível".

Emboranosdemaismunicípios não se observe omesmo nível deprofissionalização, os entrevistados de quatro municípios deixaram claro estar satisfeitos com o relacionamento do setor contábil com os gestores municipais, principalmente por receberem total apoio em suas atividades e por haver abertura para diálogos e troca de ideias, já que o gestor reconhece a importância das mudanças.

Por outro lado, E2 aponta que o relacionamento com o gestor municipal não é tão satisfatório assim:

[SIC] Há diálogo com os gestores, mas eles pensam muito em aspectos políticos e isso prejudica a gestão municipal. Acham muito grande o volume de exigências contábeis para com os municípios de pequeno porte e esse volume de exigências deixa os gestores preocupados. [...], por exemplo, alguém pediu 
um auxílio de mão de obra pra uma construção e eles preferem sacrificar para esses atendimentos políticos. Mas o setor de contabilidade está sempre dialogando com o gestor e tentando explicar a importância da contabilidade.

E4 destaca que na prefeitura onde trabalha:

[SIC] há um relacionamento satisfatório, apesar do gestor não seguir todas as orientações que o contador faz, devido sua vontade política. Os gestores não estão interessados em contabilidade, estão preocupados com outras atividades. Ele não percebe a importância, não dão o mínimo valor, mas o setor está sempre conversando com o gestor.

Além desses, outro aspecto relevante identificado é a localização da contabilidade no organograma dos municípios. Essa localização revela a importância a ela atribuída pelos gestores públicos municipais e pode indicar a vinculação dos desempenhos às linhas de autoridade e responsabilidade.

De acordo com os relatos dos entrevistados, percebeu-se que apenas no município em que a gestão é feita por um profissional formado na área, a contabilidade assume a posição de assessoria contábil e é colocada no mesmo patamar da assessoria jurídica. No caso dessa prefeitura, as assessorias estão posicionadas no organograma logo abaixo do cargo de prefeito e vice-prefeito, mesmo sendo um município de pequeno porte. Nos outros sete municípios, a contabilidade é alocada dentro de secretarias municipais, como a Secretaria da Fazenda ou a Secretaria de Finanças.

Assim, nota-se que o município do entrevistado E7, que possui gestor profissionalmente capacitado e atribui maior importância à contabilidade em seu organograma, é também o que apresenta maior nível de aderência às novas normas, conforme exposto no Quadro 1. Portanto, percebe-se que a profissionalização não só contribui com o processo de implementação, como facilita a aceitação e percepção da necessidade de mudança por parte dos demais servidores.

Tais achados vão ao encontro da afirmação de Hodgson (2006), ao destacar que a não percepção dos indivíduos quanto à importância de determinadas mudanças influencia a aceitação e institucionalização das normas, mostrando que a aceitação é algo essencial em um processo de institucionalização. Barley e Tolbert (1997) corroboram, ao afirmar que o grau no qual a instituição se encontra habituada na forma de normas, recursos e esquemas interpretativos influenciará a forma como as pessoas se comunicam e exercem poder sobre quais comportamentos sancionar ou aprovar. 


\section{Considerações finais}

As evidências do estudo revelaram que tanto o município de médio como os de pequeno porte apresentam as mesmas dificuldades no processo de adoção das reformas de contabilidade pública. As principais justificativas relatadas pelos entrevistados fundamentam-se na falta de planejamento e vontade de alguns gestores municipais, indícios que confirmam Hodgson (2006), quando afirma que a não percepção dos indivíduos quanto à importância de determinadas mudanças influencia a aceitação e adoção das normas, mostrando que a aceitação dos indivíduos é algo essencial em um processo de implementação.

Além disso, a profissionalização do gestor público se mostrou relevante no processo de adaptação de uma reforma, já que o fato de um dos prefeitos ter formação profissional pode contribuir para que os funcionários se sintam mais motivados e empenhados no atendimento das exigências. Corrobora ainda esse argumento o amadorismo constatado em algumas cidades, acompanhado da falta de profissionalização do gestor, o que implica numa gestão pouco estruturada.

Ademais, constatou-se a influência dos aspectos políticos nas atividades dos municípios, em que a adoção de procedimentos é condicionada também a fatores alheios aos contábeis, sendo atrelados às decisões políticas do gestor.

Em termos de estruturação, o campo organizacional em que as prefeituras se situam é bem estruturado e com certa homogeneidade de comportamento, uma vez que seus integrantes buscam agir de forma racional e similar uns aos outros. Esse padrão de comportamento deriva de oportunidades criadas para trocas de experiências e do apoio nas associações de municípios ou nas empresas de software.

Tais aspectos revelam forte presença de mecanismos isomórficos normativo e mimético no processo de implementação das mudanças contábeis, havendo compartilhamento de crenças e valores. Além disso, revelaram também uma lacuna no relacionamento entre os órgãos emissores da reforma e os agentes responsáveis por sua efetivação, o que poderia gerar ruídos na informação que chega aos municípios e, com isso, ocasionar erros ou atrasos no cumprimento dos prazos.

Conclui-se que a adoção de procedimentos inovadores pode ser restrita, devido à capacidade financeira e administrativa municipal, mas potencializada pela profissionalização da gestão. Nesse sentido, é de se esperar que os prazos estabelecidos em lei para a implementação de algumas normas não sejam cumpridos de igual maneira por todos os municípios, devido às disparidades existentes entre eles.

É possível inferir que, nos municípios onde as pessoas são mais capacitadas e especializadas na gestão, o processo de implementação ocorre de forma 
menos conturbada do que nos municípios em que os indivíduos não percebem a importância dessas mudanças para a melhor evidenciação do patrimônio público.

Portanto, considera-se que os objetivos propostos neste trabalho foram atendidos. Este trabalho apresentou como principal contribuição a compreensão de como está se dando o processo de aderência da reforma contábil do setor público em municípios de pequeno e médio porte, constatando que o processo gradual esperado pelos órgãos emissores tem sido mais lento e dificultoso do que se imaginava.

Como principal limitação, destaca-se a investigação da percepção dos atores apenas de uma região específica, com municípios desses portes, o que leva à sugestão de ampliação do estudo em trabalhos futuros, na macrorregião ou em outras regiões do país, a fim de estabelecer comparações e generalizações acerca de comportamentos relacionados à adequação às novas normas. Além disso, sugerem-se investigações sobre como a administração dos entes federativos tem se disciplinado para que a adoção de normas contábeis específicas seja efetivada dentro do prazo proposto pela STN.

\section{Referências bibliográficas}

BARDIN, L. Análise de conteúdo. Lisboa: Edições 70, 2011.

BARLEY, S. R.; TOLBERT, P. S. Institutionalization and structuration: studying the links between action and institution. Organization studies, v. 18, n. 1, p. 93-117, 1997.

BERgER, P. L.; LUCKMANN, T. A construção social da realidade: tratado de sociologia do conhecimento. 24. ed. Petrópolis: Vozes, 2004.

Bertulino, M. M. et al. Normas brasileiras de contabilidade aplicadas ao setor público: implicações na contabilidade municipal. Revista Controle: Doutrina e Artigos, Fotaleza, Tribunal de Contas do Estado do Ceará, v. 10, n. 1, p. 217-242, 2012.

BRASIL. Secretaria do Tesouro Nacional (STN). Manual de Contabilidade Aplicado ao Setor Público. 7. ed. Brasília: STN, 2016.

- Secretaria do Tesouro Nacional (STN). Plano de Implantação dos Procedimentos Contábeis Patrimoniais. Cartilha. Brasília: STN, 2015. 39 p. Disponível em: <https://www.tesouro.fazenda.gov.br/documents/10180/390684/PortariaSTN-548-2015-anexo-pipcp/331a2764-dc97-473a-82b0-deb3cdd2380f >. Acesso em: 15 out. 2015.

Secretaria do Tesouro Nacional (STN). Custos - Sistema de Informação de Custos. 2016. [online]. Disponível em: <http://www.tesouro.fazenda.gov.br/pt_PT/ custos>. Acesso em: 20 de junho de 2016.

BURNS, J.; SCAPENS, R. W. Conceptualizing management accounting change: an institutional framework. Management accounting research, v. 11, n. 1, p. 3-25, 2000. 
CARVAlho, C. A.; VIEIRA, M. M. F. Organizações, cultura e desenvolvimento local: a agenda de pesquisa do Observatório da Realidade Organizacional. GESTÃO. OrgRevista Eletrônica de Gestão Organizacional, v. 10, n. 3, 2012.

CARValho, C. A. P.; Vieira, M. M. F.; LoPes, F. D. Perspectiva institucional para análise das organizações. In: EnCONTRO ANUAL DA ASSOCIAÇÃo NACIONAL DE Pós-GRADUAÇÃo EM AdMINISTRAÇÃo, 1999, Foz do Iguaçu. Anais.... Foz do Iguaçu: Anpad, 1999.

CHAVLEISHVILI, G. Isomorphic processes and social legitimacy of institutionalizing municipal community safety councils (MCSCs) in Kosovo. Journal of public administration and policy research, v. 3, n. 3, p. 62-67, 2011.

Collis, J.; HUSSEY, R. Pesquisa em administração: um guia prático para alunos de graduação e pós-graduação. 2. ed. Porto Alegre: Bookman, 2005.

CRUVINEL, D. P.; LIMA, D. V. Adoção do regime de competência no setor público brasileiro sob a perspectiva das normas brasileiras e internacionais de contabilidade. Revista de Educação e Pesquisa em Contabilidade (REPeC), v. 5, n. 3, 2011.

DARÓs, L. L.; PEREIRA, A. S. Análise das normas brasileiras de contabilidade aplicadas ao setor público - NBCASP: mudanças e desafios para a contabilidade pública. In: CONGRESSO USP dE INICIAÇÃo CIENTíFICA. 2009.

DIMAGGIO, P. J.; POWELL, W.W. A gaiola de ferro revisitada: isomorfismo institucional e racionalidade coletiva nos campos organizacionais. Revista de Administração de Empresas, v. 45, n. 2, p.74-89, 2005.

. The new institutionalism in organizational analysis. Chicago, IL: University of Chicago Press, 1991.

GamA, J. R.; Duque, C. G.; AlmeidA, J. E. F. Convergência brasileira aos padrões internacionais de contabilidade pública vis-à-vis as estratégias top-dow e bottomup. Revista de Administração Pública, v. 48, n. 1, p. 183-206, 2014.

Gerigk, W.; Clemente, A.; TAfFarel, M. O impacto da Lei de Responsabilidade Fiscal sobre a gestão financeira dos pequenos municípios: o caso do Paraná. Revista de Educação e Pesquisa em Contabilidade (REPeC), v. 4, n. 3, p. 44-69, 2010.

Guerreiro, R.; Frezatti, F.; CASADo, T. Em busca de um melhor entendimento da contabilidade gerencial através da integração de conceitos da psicologia, cultura organizacional e teoria institucional. Revista de Contabilidade \& Finanças, FEA/USP, Edição Comemorativa, p. 7-21, 2006.

Guerreiro, R.; Pereira, C. A.; Rezende, A. J. Em busca do entendimento da formação dos hábitos e das rotinas da contabilidade gerencial: um estudo de caso. Revista de Administração Mackenzie, v. 7, n. 2, 2008.

Hodgson, G.M. What are the institutions? Journal of Economic Issues, v. XI, 2006.

Instituto Brasileiro de Geografia E Estatística (IBGE). IBGE Cidades. 2016. Disponível em: <http://www.cidades.ibge.gov.br/xtras/home.php>. Acesso em: 07 jun. 2016.

Instituto Brasileiro de Geografia e Estatística (IBGE). Produto Interno Bruto dos Municípios 2010-2013. 2013. Disponível em: <http://www.ibge.gov.br/home/ estatistica/economia/pibmunicipios/2010_2013/default.shtm>. Acesso em: 09 jan. 2017. 
KELM, M. L. et al. Institucionalização das iniciativas socioambientais das organizações: interfaces entre a teoria do desenvolvimento social de Habermas e o isomorfismo da teoria institucional. Cadernos Ebape. BR, v. 12, p. 401-415, 2014.

MARTINS, G. A.; THeóPHILO, C. R. Metodologia da investigação científica para Ciências Sociais Aplicadas. São Paulo: Atlas, 2007.

Melo, K. B.; Prieto, M. F.; ANDRADE, M. E. M. C. Convergência das normas brasileiras aplicadas ao setor público: um estudo exploratório no município de UberlândiaMG. Revista de Contabilidade da UFBA, v. 8, n. 2, p. 21-35, 2014.

MEYER, J. W.; ROWAN, B. Institutionalized organizations: formal structure as myth and ceremony. American Journal of Sociology, p. 340-363, 1977.

PACHECO, F. L. O isomorfismo institucional nos teatros da região metropolitana do Recife. In: Encontro Nacional dos Programas de Pós-graduação em AdMINISTRAÇÃO, 2., 2002, Recife. Anais... Recife: Anpad, 2002.

PICCOLI, M. R.; KLANN, R. C. A percepção dos contadores públicos em relação às Normas Brasileiras de Contabilidade Aplicadas ao Setor Público (NBCASP). Revista do Serviço Público. v. 66, n. 3, p. 425-448, 2015.

Quinello, R. A Teoria Institucional aplicada à Administração. São Paulo: Novatec Editora, 2007.

Ravanello, M.; Marcuzzo, J. L.; FreY, M. R. Análise da adequação dos municípios às Normas Brasileiras de Contabilidade Aplicadas ao Setor Público. Estudos do Cepe, n. 42, p. 113-130, 2015.

ScotT, W. R. Institutions and organizations: ideas, interests and identities. Sage Publications, 2007.

TOLBERT, P. S.; ZUCKER, L. G. A institucionalização da teoria institucional. In: CLEGG, S.; HARDY, C.; NORD, W. (Orgs.). CALDAS, M.; FACHIN, R.; FISCHER, T. (Orgs. brasileiros). Handbook de estudos organizacionais, modelos de análise e novas questões em estudos organizacionais. v. 1. São Paulo: Atlas, 1999. p. 194-217.

Vicente, E. F. R.; Morais, L. M.; Platt Neto, O. A. P. A reforma na contabilidade pública brasileira e o processo de convergência: implicações e perspectivas. Revista de Informação Contábil, v. 6, n. 2, p. 01-20, 2012.

\section{Gabriela Brandão Lopes}

Mestranda em Administração pela universidade Federal de Viçosa (UFV). Contato: gabrielablopes52@gmail.com

\section{Gislaine Aparecida Santana Sediyama}

Mestre em Ciências Contábeis pela Universidade Federal de Minas Gerais (UFMG). Atualmente é Professora Adjunta do Departamento de Administração e Contabilidade da UFV. Contato: gislaineyuto@gmail.com

\section{Rodrigo Silva Diniz Leroy}

Doutorando em Ciências Contábeis pelo Programa de Pós-Graduação da Universidade Federal de Uberlândia. Contato: rodrigo.leroy@ufv.br 
RSP 